\title{
BASE ECONÔMICA E DESENVOLVIMENTO LOCAL: ESTUDO DE CASO MÚLTIPLO EM MUNICÍPIOS CANAVIEIROS
}

\author{
Bruno Astolphi Montagnhan ${ }^{1}$ \\ Pery Francisco Assis Shikida ${ }^{2}$
}

\begin{abstract}
RESUMO: Este artigo tem o objetivo de comparar e analisar a importância da agroindústria canavieira como base econômica, na geração de empregos e no desenvolvimento local em dois municípios, Mirandópolis-SP e Engenheiro Beltrão-PR. Para isso utilizou-se o modelo da Teoria da Base Econômica como forma de estimar o emprego base e seu efeito multiplicador sobre o emprego não-base. Os dois municípios possuem potencialidades que permitem a especialização na produção dos derivados da cana-de-açúcar, sendo capaz de gerar um excedente para exportação. O multiplicador de emprego calculado foi de aproximadamente 2,36 em Mirandópolis-SP e de 1,93 em Engenheiro Beltrão-PR. A evolução dos indicadores de desenvolvimento local também se mostrou mais favorável em Mirandópolis-SP, comparativamente a Engenheiro Beltrão-PR.
\end{abstract}

Palavras-chave: agroindústria canavieira, desenvolvimento local, empregos

ABSTRACT: This paper has the purpose of comparing and analyzing the Sugarcane Agroindustry importance as economic base, in job generation and local development in two cities, Mirandópolis-SP and Engenheiro Beltrão-PR. For this purpose, the model of Economic Base Theory was used as a way of estimate the base employment and its multiplier effect over the non-base employment. The two cities have potentials that allow specialization in the production of sugar cane derivatives, being able to generate a surplus for export. The multiplier of calculated employment was about 2,36 in Mirandópolis-SP and 1,93 in Engenheiro Betrão-PR. The evolution of local development indicators has also shown more favorable in Mirandópolis-SP, comparing to Engenheiro Beltrão-PR..

Keywords: sugarcane agroindustry, local development, employment

\footnotetext{
${ }^{1}$ Mestre em Desenvolvimento Regional e Agronegócio pela Universidade Estadual do Oeste do Paraná UNIOESTE. E-mail: brunoastolphi@hotmail.com.

2 Professor do Programa de Mestrado e Doutorado em Desenvolvimento Regional e Agronegócio da Universidade Estadual do Oeste do Paraná - UNIOESTE. E-mail: peryshikida@ hotmail.com.
}

Recebido em: 07/10/2012

Aceito em: 23/10/2012 


\section{INTRODUÇÃO}

O objetivo deste trabalho é comparar e analisar a importância da agroindústria canavieira como base econômica, na geração de empregos e no desenvolvimento local em dois municípios, Mirandópolis-SP e Engenheiro Beltrão-PR, localizados em dois estados representativos na produção de cana-de-açúcar.

Os meios pelos quais regiões e municípios conseguem atingir um nível de desenvolvimento mais elevado e melhorar, sobremaneira, o bem-estar geral da sua população, constituem uma constante inquietação no meio acadêmico. O debate políticocientífico sobre as possíveis causas do desenvolvimento está centrado em teorias e hipóteses como os distritos industriais, as instituições, o espírito empreendedor, o capital humano e social, dentre outros (OLIVEIRA; PEREIRA, 2010).

Nesse contexto, são diversos os métodos de análise que ajudam a compreender o comportamento dos fenômenos econômicos e sociais de uma determinada localidade diante das transformações da economia nacional e internacional. Uma das primeiras teorias que se propôs analisar o processo de desenvolvimento de uma dada localidade foi a Teoria da Base Econômica, de Douglass North (1959), que tenta estabelecer uma relação entre especialização agropecuária (capaz de gerar excedente para exportação) e desenvolvimento econômico. Desse modo, a capacidade das regiões se inserirem no sistema capitalista mercantil constituiria a principal força desencadeadora do processo de desenvolvimento.

Várias foram as regiões descritas pela literatura que se desenvolveram em torno de uma base de exportação. No Brasil, de acordo com Furtado (1959), o açúcar derivado da cana foi o primeiro grande produto de exportação do país. Embora com efeitos reduzidos sobre o restante da economia, devido à utilização de mão-de-obra escrava não assalariada e ao monopólio colonial na produção, a cana-de-açúcar foi o produto que sustentou a ocupação econômica do território durante o período colonial.

Nos últimos anos, dois fatores contribuíram para o aumento da demanda internacional por produtos advindos do processamento da cana-de-açúcar. O primeiro foi a criação da Organização Mundial do Comércio (OMC) em 1994, que regulamentou o mercado internacional do açúcar, reduzindo os subsídios nos países desenvolvidos; e o segundo foi a busca por fontes renováveis de energia, aumentando o interesse dos países pelo etanol brasileiro.

A atividade canavieira está presente em 25 dos 26 estados do Brasil. Aproximadamente 1.042 municípios, ou seja, 20\% da totalidade dos municípios brasileiros 
possuem atividades relacionadas à cana-de-açúcar. Nesse contexto, muito tem se discutido sobre a importância do setor na geração de empregos e no processo de desenvolvimento local de pequenos municípios altamente especializados na produção e cana-de-açúcar e seus derivados. Este é o caso, por exemplo, dos municípios de Mirandópolis-SP e Engenheiro Beltrão-PR, que possuem sua base econômica atrelada à produção da agroindústria canavieira. Segundo dados do IBGE (2010), Mirandópolis possui 27.483 habitantes e localiza-se na mesorregião paulista de Araçatuba, distando-se a aproximadamente $600 \mathrm{Km}$ da capital São Paulo. Nos mesmos termos, Engenheiro Beltrão localiza-se na mesorregião Centro Ocidental Paranaense a $457 \mathrm{Km}$ da capital Curitiba e possui 13.920 habitantes.

A escolha dos municípios em questão, como objeto de estudo deste trabalho, deu-se pela predominância da cultura canavieira que ocupa grande parte da paisagem local desses municípios. Estes ainda possuem características históricas comuns como o período de início do desenvolvimento da cana-de-açúcar e da instalação da unidade produtora de açúcar e etanol em seus territórios; e por fim, assemelham-se quanto à origem dos investimentos na atividade, cuja iniciativa partiu da própria comunidade local.

Essa leitura soma-se a outras que pretendem construir um referencial crítico sobre os possíveis condicionantes do desenvolvimento local. Trata-se de reunir informações teóricas e empíricas capazes de auxiliar a tomada de decisões políticas que levem pequenas comunidades, inseridas em um contexto econômico globalizado, a estágios de desenvolvimento mais elevados. Ademais, a principal contribuição em medir a sensibilidade dos municípios a determinada especialização produtiva reside em identificar possíveis estratégias que impeçam o vazamento de renda proveniente da atividade, e otimizem os efeitos multiplicadores a montante e a jusante da cadeia, contribuindo para o desenvolvimento dessas localidades.

Este trabalho é composto por cinco capítulos incluindo essa introdução. O segundo capítulo versa sobre a Teoria da Base Econômica que norteia esse trabalho. No terceiro capítulo é apresentada, à luz da teoria adotada, a metodologia e os procedimentos necessários para mensurar os empregos diretos e indiretos gerados pela agroindústria canavieira nos municípios selecionados. No quarto capítulo mostram-se os resultados da pesquisa e as discussões acerca do tema. Por fim, no quinto capítulo, é apresentada a conclusão do trabalho.

\section{REFERENCIAL TEÓRICO}


A concepção fundamental que sustenta a Teoria da Base Econômica é a de que os principais determinantes do desenvolvimento de um território são os setores responsáveis por abastecer a demanda externa na forma de exportação. A produção bem sucedida de bens agrícolas a serem vendidos fora da região tem sido a forma encontrada por áreas com características pré-capitalistas para se inserirem no processo de desenvolvimento mercantil (NORTH, 1955, 1959).

A dicotomia básica que rege toda e qualquer economia divide-se em atividades base e atividades não-base. A primeira diz respeito às atividades de exportação, e a segunda às atividades de mercado local. $\mathrm{O}$ aumento da produção das atividades base teria o poder de exercer um efeito multiplicador sobre a economia local influenciando o surgimento das atividades não-base. Dessa forma, as exportações constituem a principal força desencadeadora do processo de desenvolvimento à medida que as atividades base, que vendem seus produtos para os não residentes, incentivam o desenvolvimento das atividades não-base, de mercado local, e complementares às atividades base (SCHICKLER, 1972).

É certo que a exploração da base de exportação aumenta a renda absoluta e per capita da região contribuindo diretamente para o bem-estar da população. No entanto, é o efeito indireto, provocado por esta, o mais importante, uma vez que o emprego nos setores de atividade local é diretamente dependente do emprego nas atividades de exportação. Neste ínterim, a expansão de um setor de exportação é condição necessária, porém não suficiente para o desenvolvimento (NORTH, 1959).

Como argumenta Haddad (1999), os impactos da exploração da base econômica sobre o desenvolvimento da região podem acontecer através do efeito-renda provocado pelo setor exportador, com repercussões diretas, indiretas e induzidas sobre outras atividades da economia local. Dessa forma, a renda gerada pelo setor exportador e distribuída na forma de salário é utilizada para compra de bens e serviços que satisfaçam as necessidades da população, fazendo surgir na região atividades não diretamente ligadas ao setor exportador.

A outra contribuição correspondente do processo de exportação são os efeitos de encadeamento para frente e para trás, utilizando a terminologia de Hirschman (1961). O efeito de encadeamento para trás deriva do estímulo da atividade econômica principal de uma região aos setores que produzem bens e serviços indispensáveis àquela atividade. $\mathrm{O}$ efeito de encadeamento para frente deriva do estímulo dado aos setores que utilizam como 
matéria-prima a produção da atividade econômica principal da região. Dessa forma, o aumento da produção total contribui para o desenvolvimento econômico da região.

Porém, a magnitude exata das externalidades impulsionadas pelas exportações depende de dois efeitos essenciais: a propensão marginal a consumir na área e a propensão marginal a importar. A primeira determina a parcela da renda gasta no local que será revertida para um novo ciclo de renda. A segunda corresponde à proporção da renda que se desvia do ciclo produtivo da área na forma de importações (LANE, 1977). Enquanto a região for diversificada o bastante para atender a demanda que é gerada pelo setor base, maior será a probabilidade de o gasto ocorrer na própria área (POLÈSE, 1998).

Na concepção de Haddad (1999), algumas condições são imprescindíveis para que a região se beneficie dos efeitos multiplicadores provocados pela exploração da sua base econômica: o tamanho da população, e a concentração e distribuição da renda pessoal e familiar. Quanto maior a população da região e mais igualitária a distribuição da renda, maior o mercado interno e a possibilidade de internalização da renda na compra de bens e serviços locais.

Igualmente importantes são os atributos locais como a capacidade empreendedora e a educação da população local. Quanto mais expressivos forem, maior a consciência quanto às possibilidades de diversificação da estrutura produtiva e melhores orientados estariam os recursos públicos e privados nessa direção.

Uma contradição da teoria da base de exportação é que a importância da base de exportação, e consequentemente seu efeito multiplicador sobre o restante do sistema, possui uma relação inversa ao tamanho da região. A razão é que as exportações seriam menos importantes para a demanda agregada no caso das grandes regiões. A crítica é que, por outro lado, as regiões maiores, por sua estrutura produtiva mais diversificada, teriam melhores condições de atender a demanda local, internalizando a renda das exportações. As regiões menores podem ser altamente especializadas e o consumo dar-se via importações, diminuindo o efeito multiplicador (RICHARDSON, 1981).

Especial atenção precisa ser concedida às economias fortemente dependente de uma base de exportação pouco diversificada. $\mathrm{O}$ crescimento e desenvolvimento bem sucedido ocorrem quando a especialização no setor exportador leva, gradualmente, à diversificação das atividades produtivas da região, sendo elas em novos setores de exportação ou de mercado doméstico. Dessa forma, é necessária a diversificação da produção para que a área internalize os efeitos da base e torne-se industrializada e urbanizada. Ao longo dos anos, a região, para se tornar dinâmica, deve ser capaz de iniciar com a produção de 
produtos primários e avançar na diversificação da sua estrutura de transformação até a especialização em serviços e atividades urbanas (PIFFER, 2009).

\section{METODOLOGIA}

Para identificar as atividades base (de exportação) e não-base (de mercado interno) dos municípios de Mirandópolis-SP e Engenheiro Beltrão-PR utilizou-se o cálculo do Quociente Locacional ( $Q L)$. Como argumenta Haddad (1989), o $Q L$ faz parte de um conjunto de medidas de localização e especialização produtiva, frequentemente usada na formulação de políticas de desconcentração industrial, ou com o fito de se conhecer a estrutura econômica e as potencialidades de determinado lugar. Usualmente utilizam-se informações relacionadas ao emprego como variável-base devido a maior disponibilidade e confiabilidade dos dados.

Como desde logo pode ser presumido, em um município/região haverá tantos $Q L s$ quantos forem o número de níveis de desagregação dos setores produtivos. Este estudo fez o uso do Subsetor de Atividade Econômica segundo o IBGE (SUBS-IBGE) que discrimina o número total de empregos dos municípios em 26 setores.

Utilizando a base de dados da Relação Anual de Informações Sociais (RAIS) do Ministério do Trabalho e Emprego (MTE) para o ano de 2009, uma vez que este constitui o último dado disponível da série, este estudo serviu-se da metodologia proposta por Hildebrand e Mace (1950) para calcular os $Q L s$ dos setores de atividade econômica dos municípios objetos do estudo de caso:

$$
Q L_{i j}=\frac{\frac{E_{i j}}{E_{i}}}{\frac{E_{o j}}{E_{m}}}
$$

Onde: $E_{i j}=$ emprego formal no setor $i$ do município $j ; E_{i .}=$ emprego formal no setor $i$ do estado onde se localiza o município $j ; E_{. j}=$ emprego formal em todos os setores do município $j ; E . .=$ emprego formal em todos os setores do estado onde se localiza o município $j$.

Para os setores de atividade que apresentarem $Q L$ maior que uma unidade significa que o município apresenta uma concentração maior do emprego nesse setor em relação ao seu estado de referência, qualificando-o como atividade base do município. Por outro lado, se o $Q L$ for menor que uma unidade, significa que o setor não é relevante nessa atividade 
com relação ao estado de referência, qualificando-o como atividade não-base do município.

Uma vez identificada as atividades base, cabe quantificar os empregos gerados por essa atividade que tem ligação direta com o setor exportador. Para quantificar o emprego base dos municípios de Mirandópolis-SP e Engenheiro Beltrão-PR em cada setor de atividade econômica, utilizou-se a metodologia descrita por Piffer (2009), a partir da seguinte fórmula:

$$
E B_{i j}=S_{i j}-\left[S_{t j}\left(\frac{N_{i j}}{N_{t j}}\right)\right]
$$

Em que: $E B_{i j}=$ emprego base na atividade $i$ do município $j ; S_{i j}=$ emprego na atividade $i$ do município $j ; S_{t j}=$ emprego total do município $j ; N_{i j}=$ total de emprego na atividade $i$ do estado do município $j ; N_{t j}=$ total de emprego do estado do município $j$.

Para estimar o multiplicador do emprego básico sobre o emprego total nos municípios de Mirandópolis-SP e Engenheiro Beltrão-PR, utilizou-se a metodologia utilizada por Schickler (1972):

$$
E=E B+E N
$$

Em que: $E=$ emprego total; $E B=$ emprego base; e $E N=$ emprego não-base.

Considerando que o emprego não-base corresponde a uma proporção do emprego total (a) pode-se concluir que:

$$
E N=a E \quad(0<a<1)
$$

Substituindo na equação 3:

$$
\begin{aligned}
& E=E B+a E \\
& E B=E-a E \\
& E B=E(1-a) \\
& E=\frac{1}{1-a} E B
\end{aligned}
$$

$$
E=k \cdot E B
$$

em que, $k=\frac{1}{1-a}$ representa o multiplicador de emprego dos municípios em questão. 
Utilizando-se de um nível de desagregação maior dos setores de atividade econômica, o da Classificação Nacional de Atividade Econômica - versão 2.0 (CLASCNAE 2.0), que divide a economia em 676 setores, foi possível identificar quantos empregados da agroindústria canavieira contribuem em cada setor da classificação do SUBS-IBGE.

De acordo com a CLAS-CNAE 2.0, os empregados da agroindústria canavieira fazem parte de quatro setores de atividade econômica, a saber: Cultivo de cana-de-açúcar, Fabricação de açúcar em bruto, Fabricação de açúcar refinado e Fabricação de álcool. O setor "Cultivo de cana-de-açúcar" da CLAS-CNAE 2.0 faz parte do setor "Agricultura, silvicultura, criação de animais, extrativismo vegetal, etc.” do SUBS-IBGE; e os setores "Fabricação de açúcar em bruto", "Fabricação de açúcar refinado" e "Fabricação de álcool" da CLAS-CNAE 2.0 fazem parte do setor "Indústria de produtos alimentícios, bebidas e álcool etílico" do SUBS-IBGE.

Desse modo, dos 26 setores da SUBS-IBGE os quais foram calculados os $Q L s$, os empregados da agroindústria canavieira fazem parte de 2 destes: Agricultura, silvicultura, criação de animais, extrativismo vegetal, etc.; e Indústria de produtos alimentícios, bebidas e álcool etílico. Uma vez que destes tenham sido identificados como atividade base do município, para analisar a contribuição da agroindústria canavieira no processo de geração de empregos base aplicou-se o seguinte cálculo.

$$
E B A=(N i . n i)+(N j . n j)
$$

Em que: $E B A$ = número de empregados da agroindústria canavieira que ajudam a compor o emprego base do município; $N_{i}=$ número de empregados no setor "Cultivo de cana-deaçúcar" (CLAS-CNAE 2.0); $n_{i}$ = participação percentual dos empregados no setor "Cultivo de cana-de-açúcar" (CLAS-CNAE 2.0) com relação ao total de empregados do setor base "Agricultura, silvicultura, criação de animais, extrativismo vegetal, etc." (SUBS-IBGE); $N_{j}=$ número de empregados nos setores "Fabricação de açúcar em bruto", "Fabricação de açúcar refinado" e "Fabricação de álcool" (CLAS-CNAE 2.0); $n_{j}=$ participação percentual dos empregados nos setores "Fabricação de açúcar em bruto", "Fabricação de açúcar refinado" e "Fabricação de álcool" (CLAS-CNAE 2.0) com relação ao total de empregados do setor "Indústria de produtos alimentícios, bebidas e álcool etílico" (SUBS-IBGE). 
Identificado o número de empregados da agroindústria canavieira que compõem o emprego base de Mirandópolis-SP e Engenheiro Beltrão-PR e o multiplicador de emprego (k) dos municípios, chega-se ao valor de empregos indiretos gerados pelas agroindústrias canavieiras em cada um dos municípios.

$$
E I=k \cdot E B A-E B A
$$

O EI representa o número de empregos indiretos gerados pela agroindústria canavieira nos municípios de Mirandópolis-SP e Engenheiro Beltrão-PR. Logo, o somatório de $E I$ e $E B A$ representa o total de empregos, diretos e indiretos, gerados por esse seguimento produtivo.

A fonte de dados utilizada relativa aos empregos foi fornecida pela Relação Anual de Informações Sociais (RAIS) do Ministério do Trabalho e Emprego (MTE), que capta somente os empregos formais. Os dados referentes às agroindústrias canavieiras foram disponibilizados pelas empresas, e os relativos à população foram obtidos pelo Instituto Brasileiro de Geografia e Estatística (IBGE). As informações sobre os indicadores socioeconômicos a serem analisados (renda, renda per capita, demografia, pobreza, educação, IDH e IDH-M) foram obtidas através do Atlas de Desenvolvimento Humano no Brasil, elaborado pelo Programa das Nações Unidas para o Desenvolvimento (PNUD).

\section{RESULTADOS E DISCUSSÕES}

Conforme a divisão do IBGE, o Estado de São Paulo possui 15 mesorregiões. O município de Mirandópolis faz parte da mesorregião de Araçatuba, que é formada pela união de 36 municípios. Foi elevada à categoria de município com a denominação de Mirandópolis pelo Decreto-lei $n^{\circ}$. 14334, de 30 de novembro de 1944, desmembrado dos municípios de Valparaíso, Andradina, Pereira Barreto e Araçatuba. Possui uma área de $918,801 \mathrm{Km}^{2}$ (representa aproximadamente $0,37 \%$ da área total do estado), e está distante 538 Km da capital São Paulo. A cidade está dividida em 3 distritos: Mirandópolis (sede), Amandaba e Três Alianças, possui 9.302 domicílios e a população atual estimada é de 27.483 habitantes (IBGE, 2010).

O Estado do Paraná possui 10 mesorregiões. O município de Engenheiro Beltrão faz parte da mesorregião Centro-Ocidental Paranaense, que é formada pela união de 25 municípios. Foi elevado à categoria de município com a denominação de Engenheiro Beltrão pela Lei estadual $\mathrm{n}^{\circ} 253$, de 26 de novembro de 1954, desmembrado do município 
de Peabiru e Campo Mourão. Possui uma área de $467.471 \mathrm{Km}^{2}$ (representa aproximadamente $0,24 \%$ da área total do estado), e está distante $450 \mathrm{Km}$ da capital Curitiba. A cidade está dividida em 6 distritos: Engenheiro Beltrão (sede), Figueira do Oeste, Ivailândia, Sertãozinho, Sussuí e Triângulo, possui 5.230 domicílios e a população atual estimada é de 13.906 habitantes (IBGE, 2010).

Mirandópolis é um território de formação econômica e política mais antiga que Engenheiro Beltrão. Propositalmente, este primeiro possui um tamanho relativo maior em termos de área territorial, número de domicílios e número de habitantes do que o segundo. É possível observar ainda que o espaço onde hoje se localiza Mirandópolis presenciou ciclos econômicos produtivos bem definidos, ao passo que em Engenheiro Beltrão houve sempre a existência de três ou mais atividades coexistindo ao mesmo tempo.

Dentre as semelhanças destacam-se o período de introdução da cana-de-açúcar, que praticamente se deu a partir do final da década de 1970 e início de 1980; o ano aproximado de instalação das agroindústrias canavieiras em cada município e a política governamental (o Programa Nacional do Álcool - PROÁLCOOL) que possibilitou tal feito; e o fato de que a decisão de empreender neste novo ramo produtivo partiu das próprias comunidades locais e com características predominantemente familiares.

Atualmente, apesar de em Mirandópolis a cana-de-açúcar ocupar uma porcentagem das terras agricultadas muito superior a de Engenheiro Beltrão, a capacidade instalada de produção da agroindústria canavieira é superior neste segundo município. Por conseguinte, na safra 2009/10 a produção da unidade de Engenheiro Beltrão foi demasiadamente superior a da unidade de Mirandópolis. A título de ilustração, essas informações estão organizadas no Quadro 1 a seguir.

\begin{tabular}{|c|c|c|}
\hline \multirow{2}{*}{ Características } & \multicolumn{2}{|c|}{ Municípios } \\
\cline { 2 - 3 } & Mirandópolis-SP & Eng. Beltrão-PR \\
\hline Ano de fundação & 1944 & 1954 \\
\hline Total de habitantes & 27.483 & 13.906 \\
\hline & $\begin{array}{c}1920-1935-\text { Café } \\
1935-1955-\text { Algodão } \\
\text { Ciclos produtivos } \\
1955-1980-\text { Pecuária }\end{array}$ & $\begin{array}{c}\text { 1940-1980 - Policultura (milho, } \\
\text { mandioca, arroz, feijão, hortelã, } \\
\text { café, algodão, criação de suínos, } \\
\text { extração de madeiras) } \\
1980 \text { - soja, trigo, milho, cana-de- } \\
\text { açúcar }\end{array}$ \\
\hline Ano de instalação & 1979 & 1982 \\
\hline
\end{tabular}




\begin{tabular}{|c|c|c|}
\hline $\begin{array}{c}\text { da agroindústria } \\
\text { canavieira }\end{array}$ & & \\
\hline & 8.000 ton./dia de cana-de-açúcar & 8.400 ton./dia de cana-de-açúcar \\
Capacidade & 14.000 sacas/dia de açúcar & 24.000 sacas/dia de açúcar \\
instalada & 330.000 litros/dia de etanol & 580.000 litros/dia de etanol \\
& $3,6 \mathrm{MW}$ de potência/dia & $4.00 \mathrm{MW}$ de potência/dia \\
\hline Dados da safra & 17.500 hec. cana-de-açúcar & 27.301 hec. cana-de-açúcar \\
2009/10 & 7.318 .646 ton. de cana-de-açúcar & 2.181 .128 ton. de cana-de-açúcar \\
& 77.301 ton. de açúcar & 123.141 ton. de açúcar \\
65.822 mil litros de etanol & 79.366 mil litros de etanol \\
\hline $\begin{array}{c}\mid \\
\text { Participação da } \\
\text { total cultivado } \\
\text { (2009) }\end{array}$ & $71,8 \%$ & $17,1 \%$ \\
& \multicolumn{2}{|c}{} \\
\hline
\end{tabular}

Quadro 1: Quadro comparativo das características gerais dos municípios de MirandópolisSP e Engenheiro Beltrão-PR

Fonte: Elaborado pelo autor

A medida de especialização utilizada, o $Q L$, mostrou similaridades e diferenças quanto aos setores de atividades que apresentam maior dinamismo econômico local em cada um dos dois municípios objetos de estudo. Mirandópolis-SP e Engenheiro Beltrão-PR possuem potencialidades locais que permitem a especialização produtiva em 5 setores de atividade cada, sendo que 2 destes são comuns nos dois casos, a saber: Indústria de produtos alimentícios, bebidas e álcool etílico; e Agricultura, silvicultura, criação de animais, extrativismo vegetal, etc. Como nestes dois setores estão incluídos os empregados da agroindústria canavieira, é possível afirmar que os dois municípios são especializados neste seguimento produtivo, sendo capaz de gerar um excedente para exportação. Dessa forma, a agroindústria canavieira ajuda a compor a base econômica dos dois casos em análise.

Apesar da população de Mirandópolis-SP ser duas vezes maior do que a população de Engenheiro Beltrão-PR, este primeiro município empregou 460 trabalhadores formais a menos que o segundo. No município paranaense, aproximadamente, $51 \%$ dos empregados pertencem ao setor base e $49 \%$ ao setor não-base da economia local. Já no município paulista a parcela é de $42 \%$ no setor base e $58 \%$ no setor não-base da economia local. A título de ilustração e comparação, essas informações estão organizadas no Quadro 2 a seguir. 


\begin{tabular}{|c|c|c|}
\hline \multirow{2}{*}{ Características } & \multicolumn{2}{|c|}{ Municípios } \\
\hline & Mirandópolis-SP & Engenheiro Beltrão-PR \\
\hline Atividades base $(Q L>1)$ & $\begin{array}{l}\text { - Indústria de alimentos, } \\
\text { bebidas e álcool etílico } \\
\text { - Comércio varejista } \\
\text { - Ensino } \\
\text { - Administração Pública } \\
\text { - Agricultura }\end{array}$ & $\begin{array}{l}\text { - Indústria de alimentos, } \\
\text { bebidas e álcool etílico } \\
\text { - Indústria de produtos } \\
\text { minerais não metálicos } \\
\text { - Indústria mecânica } \\
\text { - Indústria têxtil } \\
\text { - Agricultura }\end{array}$ \\
\hline Emprego total & 3.447 & 3.907 \\
\hline Emprego base & $1.457,64$ & $2.017,23$ \\
\hline Emprego não-base & $1.989,36$ & $1.889,77$ \\
\hline
\end{tabular}

Quadro 2: Atividades base e total de empregos base e não-base dos municípios de Mirandópolis-SP e Engenheiro Beltrão-PR em 2009

Fonte: Elaborado pelo autor

Conforme pode ser observado, o total de empregos diretos gerados na agroindústria canavieira de Engenheiro Beltrão-PR é, aproximadamente, 3,4 vezes maior do que de Mirandópolis-SP. Os empregos dessa atividade assumem ainda maior representatividade sobre as atividades base do primeiro município do que do segundo: no município paranaense os empregos da agroindústria canavieira representam 94\% dos empregos base do município, enquanto que no município paulista essa parcela é de 38\%.

Engenheiro Beltrão-PR gerou 3.661 empregos diretos e indiretos no setor canavieiro em 2009, o que representou 93\% do total de empregos gerados no município. Em Mirandópolis-SP foram 1.317 empregos diretos e indiretos gerados pelo setor canavieiro, o que representou $38 \%$ do total de empregos gerados no município (QUADRO 3).

\begin{tabular}{|l|c|c|}
\hline \multirow{2}{*}{ Características } & \multicolumn{2}{|c|}{ Municípios } \\
\cline { 2 - 3 } & Mirandópolis-SP & Engenheiro Beltrão-PR \\
\hline Multiplicador de emprego & 2,36 & 1,93 \\
\hline $\begin{array}{l}\text { Empregos diretos da } \\
\text { agroindústria canavieira }\end{array}$ & 662 & 2.179 \\
\hline Empregados da agroindústria & 558 & 1.897 \\
\hline
\end{tabular}




\begin{tabular}{|l|c|c|}
\hline $\begin{array}{l}\text { canavieira que ajudam a } \\
\text { compor o setor base }\end{array}$ & 759 & 1.764 \\
\hline $\begin{array}{l}\text { Empregos indiretos da } \\
\text { agroindústria canavieira }\end{array}$ & 1.317 & 3.661 \\
\hline $\begin{array}{l}\text { Total de empregos diretos e } \\
\text { indiretos da agroindústria } \\
\text { canavieira }\end{array}$ & 759 . & \\
\hline
\end{tabular}

Quadro 3: Aspectos comparativos sobre o multiplicador de emprego da base econômica e a participação da agroindústria canavieira nos municípios de Mirandópolis-SP e Engenheiro Beltrão-PR em 2009

Fonte: Elaborado pelo autor

No entanto, apesar dos números absolutos serem mais expressivos no município de Engenheiro Beltrão-PR, o multiplicador da base econômica e, portanto, seu efeito sobre a geração indireta de empregos, assumiu maior valor no município de Mirandópolis-SP. Este fato contraria a suposição da Teoria da Base Econômica que alega que o efeito multiplicador possui relação inversa ao tamanho da área. Assim, as exportações são mais importantes para a demanda agregada no caso do maior município do estudo de caso. Com isso, é possível pensar que Mirandópolis-SP, por possuir uma estrutura produtiva mais diversificada, tem melhores condições de atender a demanda agregada local, sendo mais eficiente ao internalizar a renda proveniente das exportações. O município paranaense de Engenheiro Beltrão, segundo a teoria proposta, é altamente especializado na agroindústria canavieira, no entanto, por possuir uma estrutura produtiva pouco diversificada, grande parte do consumo local dá-se via importações, reduzindo o efeito multiplicador da base econômica.

Como lembra Schwartzman (1975), as exportações são a única fonte de variações no emprego e na renda de um município. No entanto é preciso levar em consideração os vazamentos de renda que podem ocorrer através das variações na propensão a importar e a poupar, variações nos gastos do governo não local no município e pagamentos a fatores de produção que moram em outro local. Assim, o menor valor do multiplicador de emprego em Engenheiro Beltrão-PR reflete que os vazamentos de renda acontecem de forma mais expressiva neste município.

Os indicadores de desenvolvimento local mostram que os efeitos positivos proporcionados pela agroindústria canavieira foram mais significativos no município de Mirandópolis-SP, comparativamente ao município de Engenheiro Beltrão-PR. Os dois municípios em questão apresentavam taxas de crescimento negativo da população no período anterior à chegada do novo segmento produtivo. Por um lado, no caso do 
município paulista o novo cenário trouxe maior dinamismo local, interrompendo o processo de perda populacional. Por outro lado, o município paranaense conseguiu reduzir, porém não interromper a taxa de crescimento negativo da população após a chegada da agroindústria canavieira. Nos últimos anos, Mirandópolis-SP apresenta uma taxa geométrica de crescimento anual da população de 0,61\%, enquanto que em Engenheiro Beltrão-PR essa taxa é de -0,29\% (QUADRO 4).

\begin{tabular}{|l|c|c|}
\hline \multirow{2}{*}{ Características } & \multicolumn{2}{|c|}{ Municípios } \\
\cline { 2 - 3 } & Mirandópolis-SP & Engenheiro Beltrão-PR \\
\hline $\begin{array}{l}\text { Crescimento populacional } \\
\text { pré-agroindústria canavieira }\end{array}$ & $-20 \%$ & $-38 \%$ \\
\hline $\begin{array}{l}\text { Crescimento populacional } \\
\text { pós-agroindústria canavieira }\end{array}$ & $27,7 \%$ & $-11,1 \%$ \\
\hline $\begin{array}{l}\text { Taxa geométrica de } \\
\text { crescimento anual da } \\
\text { população (1980-2010) }\end{array}$ & $0,61 \%$ & $-0,29 \%$ \\
\hline PIB municipal (2008) & $\mathrm{R} \$ 117.726,20$ & $\mathrm{R} \$ 117.064,48$ \\
\hline
\end{tabular}




\begin{tabular}{|l|c|c|}
\hline Participação setorial (2008) & $\begin{array}{c}\text { Agropecuária - 10,9\% } \\
\text { Indústria - 10,2\% } \\
\text { Serviços - 78,8\% }\end{array}$ & $\begin{array}{c}\text { Agropecuária - 22\% } \\
\text { Indústria }-14,6 \% \\
\text { Serviços - 62,6\% }\end{array}$ \\
\hline PIB per capita (2008) & $\mathrm{R} \$ 4.408,40$ & $\mathrm{R} \$ 8.201,81$ \\
\hline Índice de Gini & $\begin{array}{c}1991-0,55 \\
2000-0,52\end{array}$ & $\begin{array}{l}1991-0,52 \\
2000-0,59\end{array}$ \\
\hline Pobreza (2000) & $17,6 \%$ & $27,7 \%$ \\
\hline IDH-M (2000) & 0,797 & 0,762 \\
\hline
\end{tabular}

Quadro 4: Aspectos comparativos sobre a evolução dos indicadores de desenvolvimento local dos municípios de Mirandópolis-SP e Engenheiro Beltrão-PR

Fonte: Elaborado pelo autor

Ainda que os PIBs dos dois municípios sejam praticamente iguais e o PIB per capita de Engenheiro Beltrão-PR seja aproximadamente o dobro do de Mirandópolis-SP, este último se mostrou em melhores condições de reverter a riqueza gerada localmente em benefício da sua população, tornando sua estrutura econômica e social mais desenvolvida. Seguindo as orientações de Borba (2000), isso pode ser notado quando os dados são analisados em conjunto: 1) o PIB de Mirandópolis-SP apresentou uma trajetória de estabilidade ao longo dos anos, ao passo que o PIB de Engenheiro Beltrão caracteriza-se pela grande volatilidade; 2) o setor de serviços assume maior participação no PIB de Mirandópolis, sendo essa uma característica das economias mais desenvolvidas; 3) a concentração de renda, medida pelo Índice de Gini, apresenta uma tendência de redução em Mirandópolis-SP, já em Engenheiro Beltrão-PR o oposto é verdadeiro; 4) a proporção de pessoas consideradas pobres em Mirandópolis-SP é 10\% menor do que em Engenheiro Beltrão; 5) o IDH-M de Mirandópolis-SP é superior ao IDH-M de Engenheiro Betrão-PR.

Apesar da grande importância na geração de emprego e renda local dos municípios, é importante lembrar que os dados não devam ser creditados única e exclusivamente à atuação da agroindústria canavieira. Deve-se considerar também a participação do Estado neste novo cenário, através da adoção de políticas sociais e de desenvolvimento local.

\section{CONSIDERAÇÕES FINAIS}

Este trabalho teve o objetivo de comparar e analisar a importância da agroindústria canavieira, como base econômica, na geração de empregos e no desenvolvimento local em dois municípios, Mirandópolis-SP e Engenheiro Beltrão-PR. 
Apesar dos números absolutos da agroindústria canavieira serem mais expressivos em Engenheiro Beltrão-PR (a atividade gera direta e indiretamente 93\% dos empregos do município), o multiplicador da base econômica e, portanto, seu efeito sobre a geração indireta de empregos, assumiu maior valor em Mirandópolis-SP (2,36, contra 1,93 de Engenheiro Beltrão-PR). Este fato contraria a suposição da Teoria da Base Econômica que alega que o efeito multiplicador possui relação inversa ao tamanho da área. Assim, as exportações são mais importantes para a demanda agregada no caso do maior município do estudo de caso. Com isso, é possível pensar que Mirandópolis-SP, por possuir uma estrutura produtiva mais diversificada, tem melhores condições de atender a demanda agregada local, sendo mais eficiente ao internalizar a renda proveniente das exportações.

Nota-se que, nos dois casos, foram estabelecidos os dois fundamentos básicos de todo e qualquer desenvolvimento: crescimento econômico e redução da pobreza. No entanto, o cenário mostrou-se mais favorável no município de Mirandópolis-SP comparativamente ao município de Engenheiro Beltrão-PR que, apesar de possuir uma renda per capita elevada, possui um histórico de perda populacional e aumento na concentração de renda.

Como a própria Teoria da Base Econômica assevera e os dados apresentados comprovam, a agroindústria canavieira desempenha um importante papel no crescimento e no desenvolvimento dos municípios uma vez que estimula a geração de emprego e renda, e incentivam as atividades de mercado local, comércio e serviços, dados seus efeitos de dispersão. Na ausência desta ou de outra atividade dinâmica de "exportação", os municípios estariam em uma situação inferior à atual, seguindo a mesma trajetória de outros municípios de suas mesorregiões. Entretanto, o desenvolvimento econômico local observado pode ter ultrapassado a atuação da agroindústria canavieira, devendo ser levado em consideração também a atuação do Estado neste processo. Apesar da importância de se conhecer esse limite, é difícil dizer muito a seu respeito.

Faz-se necessário salientar que, uma das limitações deste trabalho esta na defasagem temporal dos dados utilizados, a exemplo o IDH-M. Como eles são baseados nos Censos Demográficos que ocorrem somente a cada dez anos (e as estatísticas oficiais mais recentes que estão disponíveis são de 2000), após doze anos, certamente ocorreram mudanças com relação às condições observadas. Contudo, isso não inviabiliza a validade e a importância da análise feita, pois, como é consenso na literatura, os problemas da desigualdade e da concentração de renda são questões estruturais, e como tal, requerem um horizonte de tempo para serem solucionados. 
Uma das críticas associadas à base exportadora está na possibilidade de internalização de crises nacionais e internacionais que podem afetar a região fortemente dependente de um único produto de exportação. Desse modo, essas economias devem diversificar sua base exportadora, a fim de se precaver de futuros declínios na demanda do produto de exportação ou exaustão dos recursos naturais que viabilizam a atividade. Caso as atividades da agroindústria canavieira deixassem de existir, e não havendo outra atividade a substituí-la, a população de Mirandópolis-SP seria 38\% menor e a de Engenheiro Beltrão-PR, 94\% menor.

Não obstante, a grande discussão mantida nas últimas décadas é se as grandes empresas podem, ou não, desempenhar um papel dinâmico no processo de desenvolvimento local de pequenos municípios em que estão instaladas. Sobre isso, é correto afirmar que, quanto maior o tamanho da empresa, maior será a probabilidade do capital investido na atividade ser proveniente de fora da região e, consecutivamente, maior a probabilidade dos excedentes financeiros não permanecerem onde a atividade econômica acontece. Nesses termos, Souza (2008) destaca o caso do açúcar no Nordeste e da borracha na Amazônia que não conseguiram dinamizar as regiões depois que a atividade exportadora deixou de existir. As empresas de capital estrangeiro efetuavam o mínimo de gastos nas regiões que estavam instaladas e exportavam todo o excedente por elas criado.

Contrariamente a esta conjectura, Vázquez Barquero (2001) afirma que sim, é possível que grandes empresas exerçam um papel decisivo no desenvolvimento local, bastando que, para isso, atuem como empresas flexíveis, adotando medidas que fortaleçam as relações entre as unidades operativas de sua rede espacial e os territórios onde estão localizados. $\mathrm{O}$ aumento da concorrência forçou a adoção de modelos de organização mais flexíveis, dando maior autonomia no desenvolvimento de produtos e no controle dos processos de produção, comercialização e distribuição. As grandes empresas modernas procuram preservar o entorno local, incentivam a qualificação dos trabalhadores, e contribuem para a propagação da inovação e do conhecimento empresarial entre as empresas locais.

Para efeito de alcançar o objetivo proposto, este trabalho se limitou em analisar os efeitos da atividade base, constituída pela agroindústria canavieira, sobre as atividades nãobase dos municípios por meio da geração de empregos, associando-os ao processo de desenvolvimento local. Para trabalhos futuros sugere-se um estudo que mostre as novas estratégias das empresas do setor sucroenergético, no que diz respeito às relações entre 
seus fornecedores e clientes, a comunidade local e as instituições das cidades onde suas plantas industriais estão localizadas.

\section{REFERÊNCIAS BIBLIOGRÁFICAS}

BORBA, R. A. V. A cidade cognitiva: proposição para o desenvolvimento local na era do conhecimento. 2000. 344 f. Tese (Doutorado em Arquitetura e Urbanismo) - Faculdade de Arquitetura e Urbanismo, Universidade de São Paulo, São Paulo, 2000.

FURTADO, C. Formação econômica do Brasil. Rio de Janeiro: Fundo de Cultura, 1959.

HADDAD, P. R. A competitividade do agronegócio e o desenvolvimento regional no Brasil: estudo de clusters. Brasília: CNPq/Embrapa, 1999.

HADDAD, P. R. Medidas de localização e de especialização. In: HADDAD, P. R.; FERREIRA, C. M. de C.; BOISIER, S.; ANDRADE, T. A. (Orgs.). Economia Regional: teorias e métodos de análise. Fortaleza: BNB/ETENE, p. 225-248, 1989.

HILDEBRAND, G.; MACE JR., A. The employment in na expanding industrial market, Los Angeles Country, 1940-47. Review of Economics and Estatistics, 32: 341-9, ago. 1950.

HIRSCHMAN, A. A estratégia de desenvolvimento econômico. Rio de Janeiro: Fundo de Cultura, 1961.

INSTITUTO BRASILEIRO DE GEOGRAFIA E ESTATÍSTICA (IBGE). Censo Demográfico 2010. Rio de Janeiro: IBGE, 2010.

LANE, T. O multiplicador da base urbana: avaliação de sua situação atual. In:

SCHWARTZMAN, J. (Org.). Economia regional: textos escolhidos. Belo Horizonte: Cedeplar, 1977.

MINISTÉRIO DO TRABALHO E EMPREGO (MTE). Base de dados da Relação Anual de Informações Sociais (RAIS). Registros administrativos. Brasília: MTE, 2010.

NORTH, D. C. Agriculture in Regional Economic Growth. Journal of Farm Economics, 41(5), dec., 1959. Versão em português em SCHWARTZMANN, J. (Org). Economia Regional: textos escolhidos. Belo Horizonte: Cedeplar, 1977.

NORTH, D. C. Location Theory and Regional Economic Growth. Journal of Political Economy, LXIII, Jun., 1955. Versão em português em SCHWARTZMANN, J. (Org). Economia Regional: textos escolhidos. Belo Horizonte: Cedeplar, 1977.

OLIVEIRA, G. de; PEREIRA, A. da S. Da agricultura ao desenvolvimento: a transição de regiões periféricas ao capitalismo mercantil segundo Douglass North. In: $48^{\circ}$ CONGRESSO DA SOCIEDADE BRASILEIRA DE ECONOMIA E SOCIOLOGIA RURAL, 2010, Campo Grande-MS. Anais... Campo Grande: SOBER, 2010. 
PIFFER, M. A Teoria da Base Econômica e o desenvolvimento regional do Estado do Paraná no final do século XX. Tese (Doutorado em Desenvolvimento Regional) Universidade de Santa Cruz do Sul, UNISC, Santa Cruz do Sul, 2009.

POLÈSE, M. Economia urbana e regional: lógica espacial das transformações econômicas. Coimbra: APDR, 1998.

RICHARDSON, H. W. Economia regional: teoria da localização, estrutura urbana e crescimento regional. $2^{\mathrm{a}}$ ed. Rio de Janeiro: Zahar, 1981.

SCHICKLER, S. A teoria da base econômica regional: aspectos conceituais e testes empíricos. In: HADDAD, P. R. Planejamento regional: métodos e aplicações ao caso brasileiro. Rio de Janeiro: IPE/INPE, 1972.

SCHWARTZMAN, J. A. teoria da base de exportação e o desenvolvimento regional. In: HADDAD, P. R. (Org.). Desequilíbrios regionais e descentralização industrial. Rio de Janeiro: IPEA/IPLAN, p. 37-91, 1975.

VÁZQUEZ BARQUERO, A. Desenvolvimento endógeno em tempos de globalização. (Tradução: Ricardo Brinco). Porto Alegre: Fundação de Economia e Estatística, 2001. 